\title{
Anionic Polymerization of Isoprene at Low Concentrations of Polyisoprenyllithium
}

\author{
Lewis J. Fetters*
}

(December 13, 1964)

\begin{abstract}
The kinetics of polymerization of isoprene with $n$-butyllithium initiator was investigated in $n$-hexane solution over an extended concentration range of poly-organolithium. The propagation reaction was found to be first-order with regard to monomer and half-order with respect to chain anion concentration. The degree of chain anion aggregation, in the association equilibrium between active single chains and inactive associated chains, was concurrently scrutinized. The evidence accrued from the studies indicates that the associated chains exist only as binary aggregates. These experimental findings are in concert with those results obtained at higher concentrations of polyorganolithium.
\end{abstract}

\section{Introduction}

The mechanism of anionic polymerization has received some elucidation from recent studies $[1-31]^{1}$ of polymerization in homogeneous solution initiated by soluble organolithium compounds. The polymerization of such monomers as styrene in benzene and isoprene or butadiene in $n$-hexane or cyclohexane show a general absence of any termination or transfer reactions [5, 22-28, 31]. In other words, the growing chain anions retain their reactivity indefinitely. Furthermore, each initiating organolithium molecule generates one polymer chain [5, 11, 18, 22, 23].

Such homogeneous systems, therefore, have the special feature of leading to a very narrow molecular weight distribution (Poisson distribution), since all growing chains have equal probability of growth [32]. This is true only where the initiation step is not slow in comparison with the propagation reaction; otherwise a broadening of the distribution will occur. The slow occurrence of any irreversible termination during the course of the polymerization will also cause a considerable broadening of the molecular weight distribution [33-35]. This termination can result from a bimolecular reaction between an active chain-end and some monofunctional terminating impurity in the system, or from spontaneous unimolecular reactions such as a slow pseudo first-order reaction with solvent [23]. From the kinetics of the homo-polymerizations of butadiene and isoprene in benzene and concurrent molecular-weight studies [36], evidence has accrued that indicates the existence of facile transfer and termination steps. The exact nature of these reactions has not yet been elucidated fully.

It has been found that, in general, the polymerlithium species in hydrocarbon solvents are associated in pairs $[11,15,24,27,28]$. This strong electrostatic association of chain anions is absent in ethers. As a result of these studies, it is possible to

*National Academy of Sciences-National Research Council Postdoctoral Resident Research Associate.

1 Figures in brackets indicate the literature references at the end of this paper. relate the kinetics of the systems with the nature of the polymerizing chain anions. Thus, in hydrocarbon media, the following equations best describe the chain growth mechanism:

$$
\begin{gathered}
\left(R M_{j} L i\right)_{2} \stackrel{K_{1}}{\rightleftarrows} 2 R M_{j} L i \\
R M_{j} L i+M \stackrel{k_{p}}{\rightarrow} R M_{j+1} L i
\end{gathered}
$$

where $R M_{j} L i$ denotes a polymer-lithium chain; and $k_{p}$ is the velocity constant for the propagation reaction. Hence the rate controlling step for the propagation reaction is the dissociation of the chain pairs.

If the equilibrium constant, $K_{1}$, is small, then the observed rate of polymerization should be proportional to the half-power of the total chain anion concentration, both associated and dissociated. In other words the propagation reaction would show a nonintegral dependence upon the polymer-lithium concentration. This has been found to be the case $[5,13,25,28]$. Hence, the rate of polymerization can be given by the following:

$$
\frac{d[M]}{d t}=k_{p}\left[R M_{j} L i\right][M]=k_{p} K_{1}^{1 / 2}\left[\left(R M_{j} L i\right)_{2}\right]^{1 / 2}[M]
$$

This half-order dependence upon polymer-lithium concentration changes to first-order in ether solvents [25]. A notable exception to this trend is found in the polymerization of isoprene in p-dioxane by lithium catalysis. A half-order dependence of rate upon organolithium concentration is observed even though no polymer-lithium self-association has been found to exist. The kinetic behavior of this polymerization has been tentatively ascribed to solvation effects by the ether [37].

It should be pointed out that (3) is valid only when the initiation reaction is complete. Hence, it is imperative that the initiation reaction be completed prior to any investigation of the propagation step. From a kinetics standpoint, considerable complications can arise when the initiation and propagation reactions remain intertwined $[5,11,19,28,38,39,40]$. 
These difficulties can be circumvented by preinitiating $[5,22,23,25,28]$ the polymerization with a small amount of monomer at a high temperature, e.g., $50{ }^{\circ} \mathrm{C}$.

The lack of celerity in the initiation step is due, in part, to the ability of the initiating organolithium, e.g., ethyl- or $n$-butyllithium, to form associated species with polymer-lithium as well as with itself $[11,28,41,42]$. Thus, the existence of these association, dissociation, and exchange equilibria of the organometallic species that are responsible for both initiation and propagation is of great importance. The polymer-lithium self-association is exemplified by equation (1). The self- and cross-associations involving the initiating organolithium and the polymer-lithium species are shown by the equilibria (4) and (5) as follows:

$$
\begin{gathered}
(R L i)_{6} \stackrel{K_{2}}{\rightleftharpoons}(R L i)_{6-n}+n R L i \\
\left(R M_{j} L i\right)_{2}+(R L i)_{6} \stackrel{K_{3}}{\rightleftharpoons} 2\left[R M_{j} L i \cdot x R L i\right]+(R L i)_{6-2 x}
\end{gathered}
$$

where $R L i$ denotes the initiating organolithium. The exact values of $n$ and $x$ are currently uncertain. However, kinetic data implies that the unassociated form of the initiating organolithium is the active species responsible for chain initiation $[5,19,42]$ and that the above equilibria (1), (4), and (5) lie well over on the associated side over a wide concentration range.

Ethyl- and $n$-butyllithium are generally believed to be hexameric in hydrocarbon media [42], although some evidence points to lower degrees of association in some solvents $[31,43]$. Iso-, secondary-, and tertiary-butyllithium can give faster rates of initiation than $n$-butyllithium [13]. This is apparently due to the different reactivities of the lithium-carbon bond and to lower degrees of association exhibited by these isomers of butyllithium [44].

In any case, it is necessary to complete the initiation step prior to the study of the propagation reaction in order to obviate the difficulties arising from the complex dimerization and mixed association equilibria. It might be added that in ether solvents, the initiation process is, for all practical purposes, instantaneous [18, 22-24, 26].

Using viscometric techniques [24, 27], it is possible to determine the concentrations of the species $R M_{j} L i$ that are responsible for the propagation reaction. Hence, the calculation of the absolute value of the propagation rate constants is possible. For isoprene, in $n$-hexane, this was found [27] to be given by the expression:

$$
k_{p}=3.4 \times 10^{3} \exp (-4100 / R T)=8.9 L M^{-1} \sec ^{-1}
$$

at $60^{\circ} \mathrm{C}$. This compares with the expression found for styrene in benzene at the same temperature [26]:

$$
k_{p}=1.1 \times 10^{4} \exp (-3800 / R T)=34 L M^{-1} \sec ^{-1}
$$

The equilibrium constant, $K_{1}$, for the dissociation of the associated polyisoprenyl-lithium pairs, at 30 ${ }^{\circ} \mathrm{C}$ and over a concentration range of $10^{-2}$ to $10^{-3}$ moles $1^{-1}$ is of the order of $5 \times 10^{-7}[27]$. The heat of dissociation of these associated pairs is about 37 kcals $^{3}$ mole $^{-1}$. The surprisingly high activation energy (22.6 kcals mole $\left.\mathrm{k}^{-1}[25]\right)$ found for the propagation reaction includes, of course, one-half the heat of dissociation of the associated polyisoprenyllithium pairs.

In this same publication [27], several values of $K_{1}$ are recorded that are two orders of magnitude larger than the values reported above. These remarkably self-consistent values were obtained over a polyisoprenyl-lithium concentration range of $10^{-4}$ to $10^{-5}$ moles $1^{-1}$. These latter results were tentatively explained on the basis that fortuitous termination occurred, since such deleterious reactions are extremely difficult to avoid at these low concentrations. This, of course, could give rise to an apparent high value of $K_{1}$. On the other hand, these results could also be explained by assuming that the degree of chain-end association is appreciably concentration dependent within this polymer-lithium concentration range. Thus, a reexamination of the degree of polyisoprenyl-lithium self-association at very low polymer-lithium concentrations was undertaken in an attempt to resolve this question. Concurrently, kinetic measurements were also carried out. The results of this investigation are reported in this paper.

\section{Experimental Methods}

A detailed discussion of techniques and experimental procedures is available elsewhere $[22,23,25$, 27]. Experimental manipulations were accomplished with the aid of a high-vacuum apparatus at pressures of $10^{-5}$ to $10^{-6} \mathrm{~mm} \mathrm{Hg}$ to ensure the absence of water, oxygen, and other impurities to which organolithium compounds are sensitive.

All monomer and solvent purifications, initiator preparations, and polymerization reactions were carried out either directly on the vacuum line, or in sealed evacuated vessels. All reaction vessels and flasks were constructed of Pyrex glass and were thoroughly flamed under high vacuum to remove adsorbed impurities. Evacuation time was 16 to $24 \mathrm{hr}$ duration.

Isoprene (99 mole \%) was purified by successive distillations into flasks coated with freshly sublimed sodium.

$n$-Hexane was purified by standing over concentrated sulfuric acid for a minimum of two weeks, distilling onto potassium/sodium amalgam, and finally distilling into a flask coated with freshly sublimed sodium.

The purity of the solvent was confirmed by running ultraviolet absorption spectrograms on the purified product. The tests indicated the absence of benzene and other impurities detectable by U. V. analysis. 
As a final precaution, both monomer and solvent were distilled from butyllithium into the reactor immediately prior to use.

Reaction rates were measured by standard dilatometric techniques. Starkweather and Taylor [45] have shown that the contraction of a polymerizing system is directly proportional to degree of conversion. Treloar has noted [46] that this finding may not necessarily apply to all systems. There is, however, no indication that Starkweather and Taylor's conclusions do not apply to the systems studied in this work. Pre-initiated polyisoprenyllithium was used to actuate the polymerizations with $n$-butyllithium used as the initiating organolithium.

By means of a specially constructed capillary flow viscometer [27], the flow times of the polymer solutions could be measured in vacuo at the conclusion of the polymerization, both before and after termination of the active chains. Termination was effected by the addition of a minute amount of methanol.

The magnitude of the viscosity change allows a calculation of the number of chains associated by means of the well-known equation for bulk viscosity [47, 48] (or concentrated solution viscosity at fixed concentration) in the "entanglement region", i.e.,

$$
\eta=K(g M)^{3.4}
$$

where $\eta=$ bulk or concentrated solution viscosity

$M=$ molecular weight

$K=$ constant for a given polymer system

$g=$ unity for linear chains, and less than unity for branched chains.

The value of " $M$," when measured for the active chain anions, will, of course, depend on the number of such chains associated. Since the latter number has not been found, so far, to exceed two, then the two chains thus associated at their active ends may be considered as linear, and " $g$ " can be taken as unity.

Equation (8) is altered as follows for the calculation of the "association number", $N$ :

$$
\frac{\eta_{a}}{\eta_{t}} \text { or } \frac{t_{a}}{t_{t}}=N^{3.4}
$$

where $t_{a}$ and $t_{t}$ refer to the flow times of the active and terminated solutions, respectively.

It should be mentioned that care was taken to work with polymer solutions of sufficiently high concentrations where eq (8) would apply, i.e., where

$$
v_{2} M>2 M_{e} .
$$

Here, $v_{2}$ denotes the volume fraction of polymer in solution, $M$ the polymer molecular weight, and $M_{e}$ the molecular weight of a polymer segment between the loci of entanglement. The validity of equation (8) at these concentrations has been demonstrated elsewhere $[27,49]$. The value of $M_{e}$ was taken as $7,000[49]$.
The distribution of molecular weights of the linear molecules, which make up the composite, associated species, will influence the molecular weight distribution of the composite polymer chains. Therefore, since the flow behavior of these concentrated solutions is representative of the weight-average molecular weights, while in reality the number-averages are required, it is imperative to form macromolecules that closely approach the ideal monodisperse distribution in order to obtain a quantitative measure of the degree of ion-pair aggregation. Fortunately, as was previously noted, this polymerization system can lead to a very narrow distribution of chainlengths, characterized by having a very low ratio of weight-average to number-average molecular weights, viz, $\bar{M}_{w} \mid \bar{M}_{n} 乏 1.15 \quad[23, \quad 50-52]$. Thus, care was continuously exercised to insure the rapid completion of the initiation step prior to the occurrence of the bulk of the propagation reaction. This technique is identical to the "two-stage" polymerization process of Wenger [53].

\section{Results and Discussion}

\subsection{Polymer Association Ph: nom na}

Table 1 contains the viscosity data, the resulting values of the association number, $N$, and the equilibrium constant, $K_{1}$. From the value of $N$ the concentration of the dissociated polymer-lithium can be calculated readily. This method of computation is as follows:

Let $\left[R M_{j} L i\right]=$ concentration of dissociated polymer species;

$\left[\left(R M_{j} L i\right)_{2}\right]=$ concentration of associated polymer species; and

$\left[R M_{j} L i\right]_{0}=$ total concentration of all polymer species.

Hence, we have:

$$
\left[R M_{j} L i\right]_{0}=\left[R M_{j} L i\right]+2\left[\left(R M_{j} L i\right)_{2}\right]
$$

We may then let:

Thus:

$$
X=\left[\left(R M_{j} L i\right)_{2}\right] /\left[R M_{j} L i\right]
$$

\begin{tabular}{|c|c|c|c|c|c|c|}
\hline$\left[R M_{j} L i\right]_{0}$ & \multicolumn{2}{|c|}{ Flow times (sec) } & \multirow{2}{*}{$\frac{[M]_{0}}{\text { moles }^{-1}}$} & \multirow{2}{*}{$\underbrace{v_{8}^{(1)}}_{\mathrm{x} 10^{2}}$} & \multirow{2}{*}{$N^{(2)}$} & \multirow{2}{*}{$\begin{array}{c}K_{1} \times 10^{7} \\
\text { moles } 1^{-1}\end{array}$} \\
\hline moles $1^{-1} \times 10^{4}$ & active & terminated & & & & \\
\hline 2.10 & 1207 & 123.4 & 0.9 & 7.9 & 1.95 & 11.1 \\
\hline 1. 95 & 1745 & 175.1 & .9 & 7. 9 & 1. 96 & 6.5 \\
\hline 0.80 & 1291 & 134. 0 & 5 & 4.4 & 1. 95 & 4. 2 \\
\hline 0.40 & 1554 & 172.8 & 2 & 2.1 & 1. 90 & 8.9 \\
\hline
\end{tabular}

$$
X=(N-1) / 2(2-N)
$$

TABLE 1. The association of polyisoprenyl-lithium in solution at $30{ }^{\circ} \mathrm{C}$

${ }_{1} v_{2}$ was computed from the weight percent of polymer in solution. $2 N=M$ active $/ M$ terminated. 
From the above relations, it is then possible to compute:

$$
\begin{gathered}
{\left[R M_{j} L i\right]=\left[R M_{j} L i\right]_{0} /(2 X+1)} \\
{\left[\left(R M_{j} L i\right)_{2}\right]=\left\{\left[R M_{j} L i\right]_{0}-\left[R M_{j} L i\right]\right\} / 2 .}
\end{gathered}
$$

In this fashion it is possible to calculate the equilibrium concentrations of both the associated species and the dissociated (active) species and hence the equilibrium constant, $K_{1}$.

$$
K_{1}=\left[R M_{j} L i\right]^{2} /\left[\left(R M_{j} L i\right)_{2}\right] .
$$

As can be seen, the results reported in table 1 are consistent with those reported elsewhere [27] for the higher concentrations of $\left[R M_{j} L i\right]_{0}$. It therefore appears that the tentative reason presented previously to explain the high $K_{1}$ values was a correct one. Hence, it can be concluded that the active ion-pairs form aggregates made up of two macromolecules over a lithium concentration range of $10^{-2}$ to $10^{-5}$ moles $1^{-1}$.

In addition to measurements of the flow behavior of concentrated polymer-lithium solutions, dilute solution viscosity studies [28] and light scattering measurements [54] indicate that, in general, the polymer-lithium species are indeed associated in pairs in hydrocarbon media.

For a discussion of the type of bonding, i.e., multicenter electron-deficient bonds, believed to be responsible for the cluster formation of these organolithium species, the work of Coates [55] is suggested.

\subsection{Polymerization Rate Measurements}

The apparent near constancy of $K_{1}$ over the polyisoprenyl-lithium concentration range investigated indicates that the kinetics of the polymerization should likewise be self-consistent. The elucidation of this point shows this to be a valid assumption.

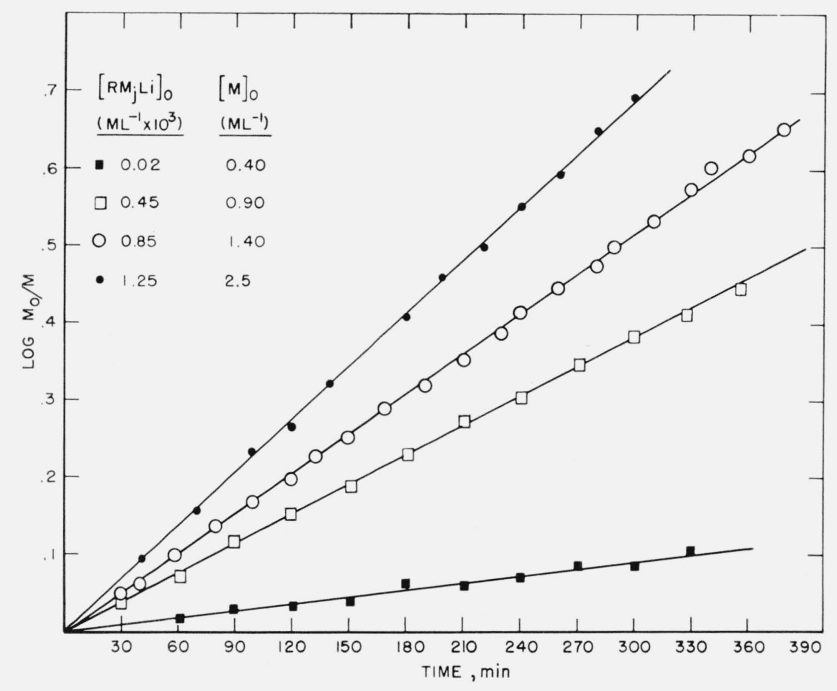

Figupe 1. First-order plots for iosprene in n-hexane $\left(30^{\circ} \mathrm{C}\right)$.

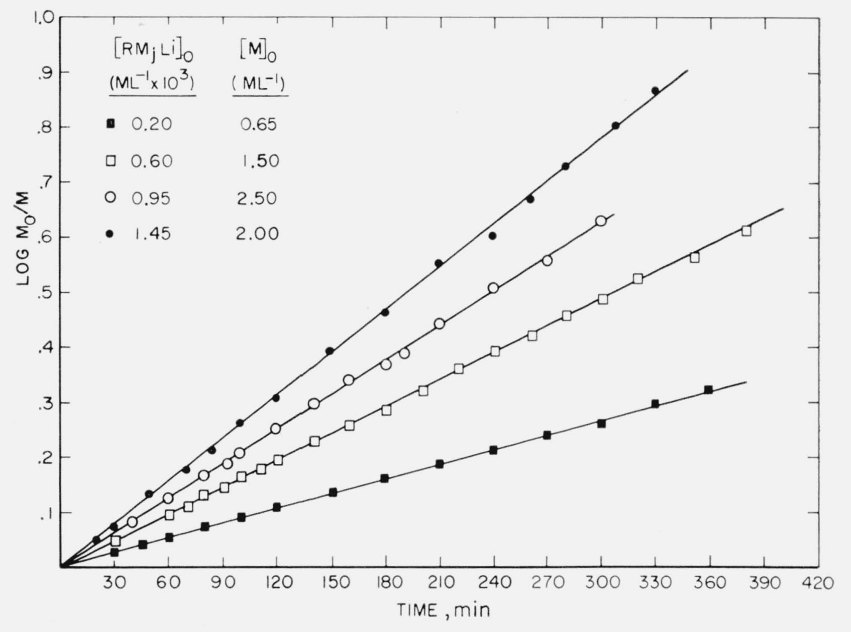

Figure 2. First-order plots for isoprene in n-hexane $(30){ }^{\circ} \mathrm{C}$

The dilatometric data are shown as first-order plots in figures 1 and 2 , where $M_{0}$ refers to initial monomer concentration and $M$ represents the concentration of monomer at any given time. It is apparent that this system shows good adherence to first-order kinetics with respect to monomer. No fall-off (or increase) in the first-order rates was detectable. These results are, of course, to be expected since the number of growing chains remains constant while the depletion of monomer is occurring. These data are recorded in table 2.

TABLE 2. First-order propagation rate constants $\left(\mathrm{k}_{1}\right)\left(30^{\circ} \mathrm{C}\right)$

\begin{tabular}{c|c|c}
\hline $\begin{array}{c}{\left[R M_{i} L i\right]_{0}} \\
\text { moles } 1^{-1} \times 10^{3}\end{array}$ & $\begin{array}{c}{[\text { Monomer }]} \\
\text { moles } 1^{-1}\end{array}$ & $k_{1} \mathrm{~min}^{-1} \times 10^{3}$ \\
\hdashline 0.02 & & \\
\cline { 1 - 1 } .02 & 0.40 & 0.70 \\
.20 & .65 & 2.00 \\
.45 & .90 & 2.95 \\
.60 & 1.50 & 3.75 \\
.85 & 1.40 & 4.00 \\
.95 & 2.5 & 4.80 \\
1.25 & 2.5 & 5.30 \\
1.45 & 2.0 & 6.00 \\
\hline
\end{tabular}

As can be seen from figure 3, the apparent rates of propagation exhibit a half-order dependency on chain anion concentration. The introduction of the constant 0.707 is brought about in the following fashion. From eq (11) we have :

$$
\left[R M_{j} L i\right]_{0}-\left[R M_{j} L i\right]-2\left[\left(R M_{j} L i\right)_{2}\right]=0 .
$$

Substitution in the equation for the associated species gives:

$$
\left[R M_{j} L i\right]_{0}-\left[R M_{j} L i\right]-2 K_{1}^{-1}\left[R M_{j} L i\right]^{2}=0 .
$$

Solving for $\left[R M_{j} L i\right]$ by use of the quadratic formula gives:

$$
\left[R M_{j} L i\right]=\frac{-1 \pm \sqrt{1+8 K_{1}^{-1}\left[R M_{j} L i\right]_{0}} .}{4 K_{1}^{-1}} .
$$




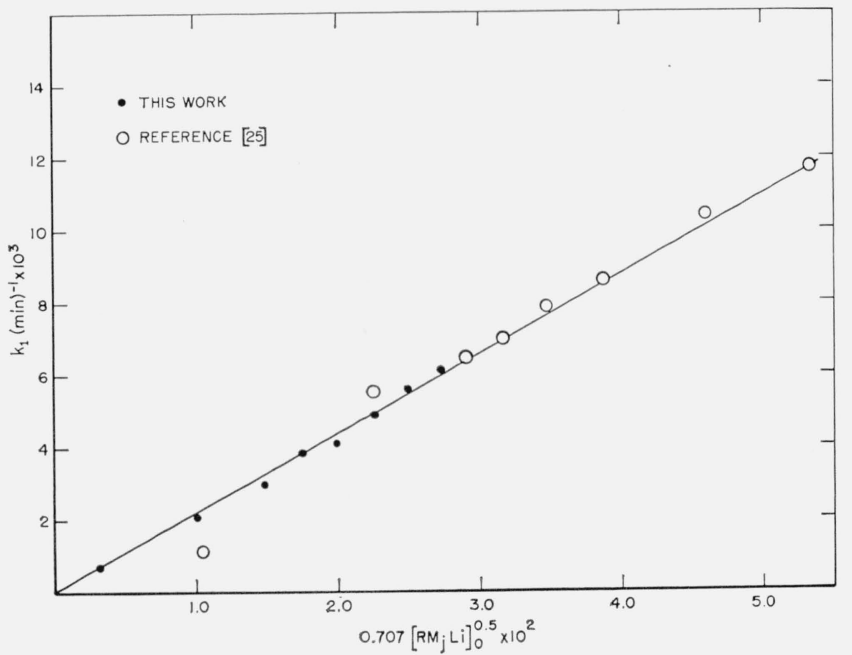

Figure 3. Dependence of iosprene rate on isoprenyl-lithium concentration.

Now since $K_{1}^{-1}>>1$ one has:

$$
\left[R M_{j} L i\right]=\sqrt{0.5 K_{1}\left[R M_{j} L i\right]_{0}} .
$$

Thus, by substitution in eq (3), we have:

$$
\frac{-d[M]}{d t}=0.707 k_{p} K_{1}^{1 / 2}\left[R M_{j} L i\right]_{0}^{1 / 2}[M] .
$$

Hence, the slope in figure 3 is equivalent to $k_{p} K_{1}^{1 / 2}$ which, in this case, is equal to 0.21 liters $^{1 / 2}$ moles $^{-1 / 2}$ $\min ^{-1}$. No significant differences could be detected in the behavior of the propagation reaction over the polymer-lithium concentration range investigated in this work and that reported by Morton et al. [25]. These later results were corrected to $30{ }^{\circ} \mathrm{C}$ by utilizing the apparent energy of activation for the propagation reaction recorded elsewhere [25]. Thus, the kinetic data concur with the data pertaining to the degree of chain anion association over the same concentration range. Kuntz [13] has reported results that are in good accord with those presented herein.

At some variance with the results reported herein are the data of, among others, Spirin [16] and Sinn [30a, b, d, g]: both of whom studied the overall polymerization reaction. Spirin reported a rather complex dependency of the propagation rate of isoprene polymerization on the total concentration of organically-bonded lithium with heptane and toluene used as solvents. The proposed polymerization scheme assumes that the degree of ionpair aggregation is concentration dependent. At low initiator concentrations $\left(10^{-5}\right.$ moles $\left.1^{-1}\right)$ the value assigned to the degree of chain-end association is two, while a value of six is applied to solutions with higher concentrations $\left(10^{-2}\right.$ moles $\left.1^{-1}\right)$ organolithium. Hence, such a solution would presumably consist of a mixture of linear $(N=2)$ and star shaped $(N=3$ to 6$)$ composite macromolecules. However, as Bueche has pointed out $[48,56]$, the existence of these star shaped macromolecules would be readily detectable since their presence would markedly influence the flow behavior of their concentrated, as well as dilute $[56,57]$, solutions. So far there has been no indication from physical measurements that any of these composite polymer chains, viz, polyisoprenyl-, polybutadienyl-, or polystyryl-lithium, possess degrees of association greater than two.

From an analysis of the experimental particulars of Spirin's work, it can be surmised that the results at high concentrations of organolithium were vitiated by incomplete initiation. It has been adumbrated [30 b], as well as conclusively demonstrated $[28,31]$, that the presence or residual initiating organolithium can serve to depress the polymerization rate in comparison to the rate of reaction obtained at an equivalent concentration of $\left[R M_{j} L i\right]_{0}$ when no initiating organolithium is present. In contradistinction to this effect is the behavior encountered when fluorenyllithium is added to an isoprene polymerization. The presence of this noninitiating organolithium effects a slight acceleration in the polymerization rate $[15,41]$.

This apparent alteration in the concentration of the active (dissociated) polymer-lithium species must be due to the cross-association existing within these systems. Thus, the concentration of the propagating polymer-lithium chains will be dependent upon the concentrations of the two organolithiums and on the respective equilibrium constants of the various and divers reactions, viz, eqs (1), (4), and (5). The concentration of the dissociated initiating organolithium would likewise be influenced in a similar fashion.

The existence of an equilibrium of the type shown in equation (5) is demonstrated by the decrease in the viscosity of polymer-lithium solutions on the addition of nonpolymeric organolithiums [28, 36, 41]. The polyisoprenyl- and polystyryl-lithium selfassociated species are disrupted, albeit somewhat reluctantly, by organolithium compounds such as fluorenyl-, ethyl-, and $n$-butyllithium. The ability of these organolithiums to disrupt polyisoprenyllithium dimers changes in the following order: fluorenyl- $>>$, ethyl- $>$, $n$-butyllithium. A given amount of one of these organolithiums will disrupt the dimers of polystyryl-lithium with somewhat greater facility than those of polyisoprenyl-lithium. These data have been recorded, in part, elsewhere $[11,15]$. The existence of these cross-associated species was initially forecast by Korotkov [2] and Tobolsky [4]. As might be expected dissimilar polymer-lithium species also form cross-associated composite macromolecules [36]. This behavior has its parallel in the formation of the cross-associated complexes resulting from the confluence of ethyl- and $t$-butyllithium [58].

At present it should not be assumed that the crossassociated aggregates, containing the polymeric and nonpolymeric organolithiums, consist of only one unique structure since various intermediates may also participate in the overall equilibrium. The same situation may also apply to the initiating 
organolithium. Szwarc and Smid [59] have also called attention to this point.

It is perhaps pertinent to note that some evidence has accrued that indicates that the cross-associated species are made up exclusively of one polymerlithium chain and one initiating organolithium molecule $[28,36,41]$. These complementary results $[28,36,41]$ are based on the assumption that the initiating organolithium is completely dissociated at polymerization concentrations. Since this assumption contradicts the information concerning the apparent high degrees of association $[31,42,60]$ exhibited by these initiating organolithiums at somewhat higher concentrations, a decision as to whether this relatively simple, and thus attractive, picture of a $1 / 1$ ratio of components in the crossassociated composite species is a correct interpretation, must currently be left in abeyance.

In addition, it has been shown that chain initiation can yet be occurring during the period of the observed maximum in the polymerization reaction. This phenomenon has been observed in the polymerization of isoprene in hexane or cyclohexane [31] and for styrene in benzene [5, 19,61]. Under certain conditions the polymerization can reach completion prior to the cessation of the initiation reaction $[28,31,40]$. This will be particularly true when the ratio of monomer to catalyst is low and the ratio of the apparent rates of propagation to initiation is high [40, 62]. Thus it must be emphasized that the attainment of a period of maximum rate in the polymerization reaction is not necessarily correlated with the completion of the initiation step. It is therefore apparent that the prime prerequisite for the attainment of meaningful kinetic data pertaining to the propagation process is the complete conversion of the initiating organolithium, e.g., ethyl- or $n$-butyllithium, to polymer-lithium. In this way it is possible to disentangle the individual steps of the overall process.

Sinn $[30 \mathrm{a}, \mathrm{b}, \mathrm{g}]$ has reported results similar to Spirin's for isoprene polymerization in heptane. The "overall rate" was found to be proportional to $[R L i]_{0}{ }^{1 / n}$ with $n$ equal to 3 at low concentrations and equal to 6 at high catalyst levels and $[R L i]_{0}$ denoting the total concentration of organically bonded lithium. The range in concentration of $[R L i]_{0}$ was from $10^{-2}$ to $10^{-5}$ molar. Apparently the term "overall rate" was meant to signify the combined rates of both the initiation and propagation reactions. In order to account for these low orders of reaction, it has been proposed that the associated polyisoprenyl-lithium chain anoins exist as preponderantly trimeric and hexameric cruciform macromolecules [38].

At catalyst levels greater than $10^{-2}$ molar, Sinn has observed a virtual independence of polymerization rate with respect to organolithium concentration. Identical behavior has been reported by other workers for isoprene $[2,63]$ and styrene $[61,64]$ polymerizations in hydrocarbon media. Taylor [31] has unequivocally shown that this effect is due to the presence of residual initiating organolithium. The data of Kuntz [13] also lend credence to this interpretation.
Sinn has also studied [30d] the $n$-butyllithium initiated polymerization of isoprene, at $20{ }^{\circ} \mathrm{C}$, at extreme dilutions of initiator, i.e., from $10^{-4}$ to $5 \times 10^{-7}$ moles $1^{-1}$. A log-log plot of the "initial rate" versus $[R L i]_{0}$ results in a convex curve with the slope of its tangent equal to one at approximately $10^{-5}$ moles $1^{-1}$ of $[R L i]_{0}$. At higher catalyst concentrations the value of the slope rapidly decreases whereas at concentrations less than $10^{-5}$ moles $1^{-1}$ the slope increases, eventually becoming somewhat greater than two. Hence Sinn concludes that in this low catalyst range the order of the reaction exceeds two. To explain this phenomenon he has postulated that the propagation reaction involves an "activated" molecule formed by an association of a monomer unit with a dissociated chain anion. This species then reacts in turn with a pair of associated chain-ends to form a trimeric associate with the activated monomer then being incorporated into the chain with which it was originally associated. He therefore concludes that the rate determining step is the formation of the trimeric associate. This supposedly takes place only when the concentration of $\left[R M_{j} L i\right]>\left[\left(R M_{j} L i\right)_{2}\right]$. Utilizing the values of $K_{1}$ reported here and elsewhere [27] the condition of $\left[R M_{j} L i\right]>\left[\left(R M_{j} L i\right)_{2}\right]$ is meet, at $20^{\circ} \mathrm{C}$, when the concentration of $\left[R M_{j} L i\right]_{0} ₹ 10^{-6}$ moles $1^{-1}$.

It is possible that the high order of reaction observed at the extreme attenuations of added $n$-butyllithium may be an artifact. At these low concentrations a small amount of termination would lower the concentration of organically-bonded lithium. This would result in the appearance of anomalously slow rates of polymerization when compared to the rates of reaction obtained at higher catalyst concentrations. On the other hand, it is readily discernible that at successively greater dilutions of polymer-lithium the concentration of dissociated (active) macromolecular lithium will constitute an increasingly greater percentage of the total chain-anion concentration. Hence the dependency of the rate of polymerization on $\left[R M_{j} L i\right]_{0}$ will gradually approach first-order.

In order to reconcile the diverse kinetic results obtained at the various concentrations of $n$-butyllithium employed, Sinn et al. [38], developed a rather elaborate mathematical treatment. The frequency factor for propagation is found to have the somewhat bizarre value of $10^{14.2}$, and this is rationalized in terms of an entropy of solvation. This value of the temperature-independent factor $A$ is markedly greater than that reported in eq (6).

Despite the explosive developments which have characterized the field of organolithium polymerization in the last decade, the elucidation of many features pertinent to the initiation and chain growth reaction is currently incomplete. In order to study the overall polymerization process in hydrocarbon media, it is necessary to be cognizant of such details as, for example, the value of the rate constant for the initiation reaction, the kinetic order of the initiation with reference to each reactant, the activation energy of the initiation, the nature of any 
solvent effects, the effects of impurities resulting from the accidental destruction of the initiating organolithium, the association state of the organolithium species involved, and the nature of any cross-association between the various organolithiums in solution. Although these reactions occur in homogeneous medium, little is known about the actual nature of the dissociated "anionic" organolithium entities. Unlike the free radical systems, where the growing chain has been unequivocally identified as a free radical, the precise character of these organolitlium entities has yet to be fully elucidated. As a consequence, the question as to why lithium catalysis results in predominately cis-1,4 polyisoprene in hydrocarbon media [1] is not yet completely answered. The nature of the bonding' responsible for the cluster formation of organolithiums is currently somewhat obscure. Further work is obviously necessary before truly adequate comment can be made concerning the field of organolithium polymerizations.

Note Added in Proof-A study of the $n$-butyllithium initiated polymerization of isoprene in cyclohexane has appeared [65]. The order of the propagation reaction in organolithium was found to be one-quarter. This was correlated with a degree of association of four as ascertained by light scattering measurements. In contrast to these results are the findings of Francois [28] and Taylor [31]. Both groups reported an order of one-half in isoprenyllithium for the isolated propagation reaction when run in cyclohexane and degrees of chain end association close to two from viscosity measurements. Hsieh [66] reported an order for the propagation reaction in organolithium of one-half for $\left[R M_{j} L i\right]_{0}>10^{-2}$ molar and one-third when $\left[R M_{j} L i\right]_{0}$ was $10^{-4}$ to $10^{-2}$ molar. No attempt was made to ascertain the degree of carbanion association. Use [36] of 1,1-diphenyl- $n$ hexyllithium as an initiator indicates an order of one-half for the propagation reaction in cyclohexane with respect to isoprenyllithium.

\section{References}

[1] R. S. Stearns and L. E. Forman, J. Polymer Sci. 41, 381 (1959).

[2] A. A. Korotkov, N. N. Chesnokova, and L. B. Truchmanova, Vysokomol. Soedin. 1, 46 (1959); Rubber Chem. and Tech. 33, 610 (1960).

[3] Yu. L. Spirin, A. R. Gantmakher, and S. S. Medvedev, Vysokomol. Soedin. 1, 1258 (1959).

[4] K. F. O'Driscoll and A. V. Tobolsky, J. Polymer Sci. 35, 259 (1959).

[5] D. J. Worsfold and S. Bywater, Can. J. Chem. 38, 1891 (1960).

[6] Yu. L. Spirin, D. K. Polyakov, A. R. Gantmakher, and S. S. Medvedev, Vysokomol. Soedin. 2, 1082 (1960).

[7] K. Kuwata, Bull. Chem. Soc. (Japan) 33, 1091 (1960).

[8] R. C. P. Cubbon and D. Margerison, Proc. Chem. Soc. (London), 146 (1960).

[9] D. J. Worsfold and S. Bywater, J. Chem. Soc., 5234 (1960).

[10] E. N. Kopacheva, A. Dolgoplosk, and E. M. Kuznetsova, Doklady Akad. Nauk S.S.S.R. 130, 1253 (1960).

[11] M. Morton, E. E. Bostick, and R. A. Livigni, Rubber and Plastics Age 42, 397 (1961).

[12] J. Minoux, B. Francois, and C. Sadron, Makromol. Chem. 44, 519 (1961).

[13] I. Kuntz, Polymer Preprints 2, [2], 68 (1961); J. Polymer Sci. 2A, 2827 (1964).

[14] C. E. Rogers, Polymer Preprints 2, [2], 75 (1961).

[15] M. Morton, N. Calderon, L. J. Fetters, and J. F. Meier, Polymer Preprints 2, [2], 310 (1961).

[16] Yu. L. Spirin, A. R. Gantmakher, and S. S. Medvedev, Doklady Akad. Nauk S.S.S.R. 146, 368 (1962).
[17] Yu. L. Spirin, A. A. Arest-Yakubovich, D. K. Polyakov, A. R. Gantmakher, and S. S. Medvedev, J. Polymer Sci. 58, 1181 (1962).

[18] S. Bywater and D. J. Worsfold, Can. J. Chem. 40, 1564 (1962).

[19] R. C. P. Cubbon and D. Margerison, Proc. Roy. Soc. 268A, 260 (1962)

[20] G. C. East, P. F. Lynch, and D. Margerison, Polymer 4, 139 (1963).

[21] J. Minoux, Makromol. Chem. 61, 22 (1963).

[22] M. Morton, A. A. Rembaum, and J. L. Hall, J. Polymer Sci. 1A, 461 (1963).

[23] M. Morton, E. E. Bostick, and R. G. Clarke, J. Polymer Sci. 1A, 475 (1963).

[24] M. Morton, L. J. Fetters, and E. E. Bostick, J. Polymer Sci., Part C, [1], 311 (1963)

[25] M. Morton, E. E. Bostick, R. A. Livigni, and L. J. Fetters, J. Polymer Sci. 1A, 1735 (1963).

[26] M. Morton, L. J. Fetters, and J. F. Meier, 145th Am. Chem. Soc. Meeting, New York, September 1963.

[27] M. Morton and L. J. Fetters, J. Polymer Sci. 2A, 3311 (1964).

[28] B. Francois, V. Sinn, and J. Parrod, J. Polymer Sci. Part C, [4], 375 (1964).

[29] S. S. Medvedev and A. R. Gantmakher, J. Polymer Sci. Part C, [4], 173 (1964).

[30] a. C. Lundborg and H. Sinn, Makromol. Chem. 41, 242 (1960); b. H. Sinn and C. Lundborg, ibid. 4\%, 86 (1961); c. H. Sinn and O. T. Onsager, ibid. 52, 246 (1962); d. H. Sinn and O. T. Onsager, ibid. 55, 167 (1962); e. H. Sinn and W. Hofmann, ibid. 56, 234 (1962); f. H. Sinn and F. Bandermann, ibid. 62, 134 (1963); and g. H. Sinn and F. Patat, Angew. Chem. 75, 805 (1963).

[31] G. L. Taylor, Ph. D. Dissertation, University of Akron, 1964.

[32] P. J. Flory, Principles of polymer chemistry, p. 338 (Cornell University Press, Ithaca, New York, 1953).

[33] B. D. Coleman, F. Gornick, and G. Weiss, J. Chem Phys. 39, 3233 (1963).

[34] T. A. Orofino and F. Wenger, J. Chem. Phys. 35, 532 (1961).

[35] M. Szwarc and M. Litt, J. Phys. Chem. 62, 568 (1958)

[36] L. J. Fetters (unpublished results).

[37] J. F. Kenney, Ph. D. Dissertation, University of Akron, 1964 .

[38] H. Sinn, C. Lundborg, and O. T. Onsager, Makromol. Chem. 70, 222 (1964).

[39] L. Reich and S. Stivala, Makromol. Chem. 53, 173 (1962).

[40] E. Bauer and M. Magat, J. Chim. Phys. 47, 841 (1950).

[41] L. J. Fetters, Ph. D. Dissertation, University of Akron, 1962 .

[42] D. Margerison and J. P. Newport, Trans. Faraday Soc. 59, 2058 (1963) and references included therein.

[43] R. Piotrovski and M. Ronina, Doklady Akad. Nauk. S.S.S.R. 115, 737 (1957).

[44] M. Weiner, G. Vogel, and R. West, Inorganic Chem. 1, 654 (1962).

[45] H. Starkweather and G. B. Taylor, J. Am. Chem. Soc. 52, $4708(1930)$

[46] F. E. Treloar, Polymer 1, 513 (1960).

[47] T. G Fox, B. S. Gratch, and S. Loshaek, Rheology, Vol. 1, ed. F. Eirich, chap. 12, p. 443 (Academic Press, Inc., New York, 1956).

[48] F. Bueche, J. Chem. Phys. 40, 484 (1964); J. Polymer Sci. 41, 551 (1959).

[49] L. J. Fetters, J. Res. NBS 69A, 33 (1965).

[50] N. Calderon and K. W. Scott, J. Polymer Sci. 3A, $551(1965)$.

[51] S. E. Bresler, A. A. Korotkov, M. I. Mosevitsky, and I. Ya. Poddubnyi, Zhur. Tech. Fiz. 28, 144 (1958).

[52] L. Gold, J. Chem. Phys. 28, 91 (1958).

[53] F. Wenger, Makromol. Chem. 64, 151 (1963).

[54] A. F. Johnson and D. J. Worsfold, J. Polymer Sic. 3A, 449 (1965).

[55] G. E. Coates, Organometallic compounds, (2nd Ed., John Wiley \& Sons, Inc., New York, N.Y., 1960).

[56] M. Morton, T. E. Helminiak, S. D. Gadkary, and F. Bueche, J. Polymer Sci. 5\%, 471 (1962). 
[57] T. A. Orofino and F. Wenger, J. Phys. Chem. 67, 556 (1963).

[58] M. A. Weiner and R. West, J. Am. Chem. Soc. 85, 485 (1963).

[59] M. Szware and J. Smid, Progress in reaction kinetics Vol. 2, chap. 5, p. 219 (Pergamon Press, Oxford, 1964).

[60] T. L. Brown, R. L. Gerteis, D. A. Bafus, and J. A. Ladd, J. Am. Chem. Soc. 86, 2135 (1964).

[61] J. L. Hall, Ph. D. Dissertation, University of Akron, 1962.
[62] M. Szwarc, Fortschritte Hochpolymeren-Forschung 2, 275 (1960).

[63] R. A. Livigni, Ph. D. Dissertation, University of Akron, 1961.

[64] F. J. Welch, J. Am. Chem. Soc. 81, 1345 (1959).

[65] D. J. Worsfold and S. Bywater, Can. J. Chem. 42, 2884 (1964).

[66] H. Hsieh, J. Polymer Sci. 3A, 173 (1965).

(Paper 69A2-337) 